\title{
An Integrated Approach for Understanding Health Behavior; The I-Change Model as an Example
}

\author{
*Hein de Vries \\ Department of Health Promotion, Maastricht University, Europe
}

Submission: March 02, 2017; Published: March 09, 2017

*Corresponding author: Hein de Vries, Professor in Health Communication, Department of Health Promotion, School for Public Health and Primary Care (CAPHRI) Maastricht University POB 6166200 MD Maastricht The Netherlands, Tel: 003143 3882415/2410/2406;

Fax: 003143 3671032; Email: hein.devries@maastrichtuniversity.nl

\section{Abstract}

This paper discusses challenges in utilizing findings and constructs from different (health behavior) theories. There is a multitude of theories that can be used, but the question is what to do with so many theories. As a result there is debate about the need for integrating health behavior theories. Opponents of integrating theories suggest that this may lead to a theory of everything without adding anything. Supporters, however, see advantages of such an approach. Integration is more than simply combining theories. Combining theories implies using a simple additive model. Integration, however, implies critical testing of these constructs, and constructs will only be added if they have supplementary value theoretically and empirically and will lead to developing and testing new hypotheses. This paper outlines what the advantages of critical testing and integration of theories could be, using the Integrated-Change Model as an example.

Keywords: Integration; health behavior; theories; ecological model; The I-Change Mode

Abbreviations: SCT: Social Cognitive Theory; HBM: Health Belief Model; TPB: Theory of Planned Behavior; TTM: Trans Theoretical Model; PAPM: Precaution Adoption Process model; MAP; Model of Action Phases; HAPA: Health Action Process Approach

\section{Introduction}

Health behavior theories and models can be used for various reasons, such as trying to understand health behavior and its determinants, to change health behavior, to realize advances in science, but also for translating science into practice. Well known theories and models used in health behavior science are, for instance, Social Cognitive Theory (SCT) [1], the Health Belief Model (HBM) [2], the Theory of Planned Behavior (TPB) [3], and the Trans Theoretical Model (TTM) [4]. These models did not develop out of the blue but are also results from integration of constructs from, and findings of other theories and models. Social cognitive theory developed from social learning theory that incorporated differential association theory principles, operant conditioning principles and added self-efficacy. The theory of Planned Behavior (TPB) - resulting from the Theory of Reasoned Action [5] and the TTM both added self-efficacy. TTM also incorporated several principles from 18 therapy systems [4].

Theories and models summarizing the main theoretical elements all reduce reality in order to provide an overview of main principles and pathways of behavior change. Models and theories are also subject to criticism, not only because of this reductionism, but also because of stands taken, methodology used or the discovery of new (combinations) of factors, which may lead to suggestions to extend [6] or completely abolish a theory such as TPB, see e.g. Sniehotta et al. [7]. Yet, TRA and TPB resulted in a tremendous improved understanding of the fact that at least four different factors may influence behavior, whereas the notion of correspondence of measurement clearly indicated that if we want to predict behavior 'A' that we also need to assure that questions measuring the determinants also refer to the very same behavior ' $A$ '.

TTM contributed by indicating that behavior change can also be interpreted in terms of stages rather than a dichotomous process (e.g. sick versus cured) and that those in preparation to change may have different needs than those not even contemplating change. Yet criticisms exist on the time algorithm used for distinguishing motivational levels [8] and the exact number of stages $[9,10]$. Health behavior theories can also have 


\section{Psychology and Behavioral Science International Journal}

multiple purposes. For instance TPB can be used for identifying the most important factors to address in interventions. Yet, TPB is less suitable as a behavior change model as intervention development requires suggestions on appropriate and effective behavior change techniques for changing a particular determinant. Here, other models such as intervention mapping of Bartholomew and colleagues [11] may fit better.

The number of theories and constructs used in health behavior science is enormous. Michie and colleagues [12], for instance, identified at least 1700 constructs used in 83 theories, which are not all distinct [13-16] or can be operationalized separately [17]. Hence, should we conclude that we have too many theories of behavior [18]? Yet, researchers fail "to carry out the winnowing process" needed for scientific progress [13] p.324. Noar and Zimmermann [15] indicated that health behavior theories need to describe the important variables and factors, how they relate and interact. A challenge will then be how to move forward and how to do this. On important distinction is to distinguish between combining and integrating theories.

\section{Combining versus Integrating}

Progress in health psychology will be contingent on testing numerous theories [19] and finding alternative pathways. Should this testing imply combining or integrating theories? I refer to combining when one or several constructs from theory ' $\mathrm{A}$ ' are added to another theory ' $\mathrm{B}$ '. Integration implies critical testing of these constructs. Constructs can only be added if these will lead to developing and testing new hypotheses and have supplementary significance theoretically or empirically. Combining theories, however, implies a simple additive model. An additive model has a couple of dangers, as it does not critically reflect on the added value of new construct and may imply reinventions of wheels [18]. Integrating is more than simply combining and should lead to added value [20]. Although one could argue that the latter stand should be logical, critical testing of constructs and its assumptions does not always happen or demonstrate the added value of new constructs. For instance, whereas the rationale for measuring attitudes via pros and cons in TTM is clearly outlined and assessed [21] the evidence for the added value of the processes of change is less clear [22-24]. Concerning TPB there is criticism on the fact that no attention is paid to the role of earlier behavior and habit, as studies suggest added value of inclusion of them [25-30].

Despite weakness in theories, we want to keep its strengths but eliminate the weaknesses. For instance, a strong point of TPB is its clear description of the four factors that determine behavior. Yet, refinement of these constructs may be needed as different factors within these constructs may exist. Further, TRA and TPB pay relatively little attention for the determinants of attitudes, subjective norms and self-efficacy. Finally, TRA and TPB pay less attention to factors that may bridge the gap that exists between intention and behavior. So, how can we learn from integrating ideas and constructs from other theories?

With respect to the attitude construct, several researchers have outlined the existence of different dimensions, such as the existence of expected advantages and disadvantages, also referred to as the pros and cons of a behavior [21,31-33]. The added value of testing this distinction is that studies showed that the cons of a behavior may be more important for those who are not motivated to change, whereas the pros of a health behavior may be more important for those already motivated to change $[21,34,35]$. Simply sticking to one overall attitude construct would not have identified this finding which also implies that better targeted interventions can be developed. Another set of studies assessed the added value of discriminating between rational and emotional beliefs [36-38] also showing that emotional cons may sometimes be the most powerful predictor of behavior [39]. Concerning social influences, studies revealed the added value of Bandura's construct of social modeling and social pressure [25]. The importance of modeling is now also referred to as descriptive norms [40]. Concerning self-efficacy different, self-efficacy domains are now recognized $[33,41]$ and findings suggest that self-efficacy expectations may be most important when respondents are motivated to change $[42,43]$.

Other aspects concern the importance of different phases of change. Theories such as TPB recognize a motivational phase, but pay less explicitly attention to premotivational and postmotivational phases and factors that may be important during these phases. There is discussion as to whether knowledge and risk perceptions are important factors for understanding and changing behavior. A researcher developing questionnaires or interventions using TPB might conclude that addressing these factors is not important. Yet, studies showed these constructs may function as distal awareness factors influencing behavior via attitudes and self-efficacy $[44,45]$ and are thus important factors in this awareness or premotivational phase. Concerning post-motivational factors, several studies have outlined that intentions do not perfectly predict behavior. Sheeran (46) found that intentions explained $58 \%$ of the behavioral variance. The importance of action planning as a determinant as well as a behavior change strategy to translate intentions into behavior has been outlined in several publications. Action planning can be regarded as a fifth factor besides attitudes, social influence beliefs, self-efficacy and intentions to predict behavior $[47,48]$.

Several studies suggest that stages or motivational phases exist. Stage theories of health behavior assume that individuals pass through qualitatively different stages on their way to the adoption of health behaviors. Examples of stage theories are the Trans Theoretical model [3] the Precaution Adoption Process model (PAPM) [49], the I-Change model [50,51], the health action process approach [52] or the Model of Action Phases (MAP) [53]. Although findings supporting the evidence base for these theories is not fully consistent, and these models can also 


\section{Psychology and Behavioral Science International Journal}

be subject to criticism [8], multiple findings suggest qualitative differences between three stages that can be referred to as premotivational, motivational, and post motivational, $[16,54,55]$ . Action planning has been identified as a crucial factor for the post-motivational phase, to better understand why intentions are or are not translated into behavior [48,56-58] or can prevent relapse [57]. Research indicates that at distinct types of action planning are relevant: preparatory planning to help people to undertake a behavior change attempt and coping planning for actions to cope with difficult situations. Additionally, plan enactment, implying the realization of these plans, appears to be an additional important construct [59].

\section{Critical Interactions}

Integration of models is more than simply adding up theories, and requires a critical analytic approach to identify whether and when certain constructs have added value and how they interact with each other. The I-Change Model, for example, assumes that the impact of factors may differ per motivational phase, those variables and factors are connected and influence each other thus acknowledging that a simple main factor paradigm oversimplifies reality [60]. Traditional social cognitive models interpret the impact of motivational factors on behavior as an additive model, whereas an interactive approach may better address the complex reality where multiple factors have a reciprocal and interactionistic relationship [60]. Studies, for instance, demonstrate interaction effects of self-efficacy and action planning on behavior [61-64] and demonstrate that action planning may only be beneficial for respondents with high self-efficacy [64].

Integration does not necessarily lead to one similar solution. When comparing integrative models, for instance the Health Action Process Approach (HAPA) model [52] (Figure 1) and the I-Change Model (Figure 2), one can notice similarities and differences. Both models assume the existence of motivational phases, but differ in certain postulates. For instance, the HAPA model assumes an equal role of risk perceptions, outcome expectations (attitude) and task self-efficacy. The I-Change Model, however, postulates that risk perceptions play a more distal role (in the pre-motivational phase) in combination with cognizance awareness of one's own behavior, knowledge and perceived cues. Both the I-Change Model [33,65] and the HAPA model postulate different types of self-efficacy [66], but the HAPA model has postulated different roles for different types of self-efficacy. These differences in postulates offer an interesting challenge to assess which will receive support as well the conditions for such support. Another example, Hagger \& Chatzisarantis [67] integrated the Theory of Planned Behavior and Self-Determination Theory [68] and found support for the role of self-determinated motivation as a antecedent factor influencing mostly attitude and self-efficacy. Yet, SDT contains more constructs and a more vigorous test is thus needed (Figures 1 \& 2).
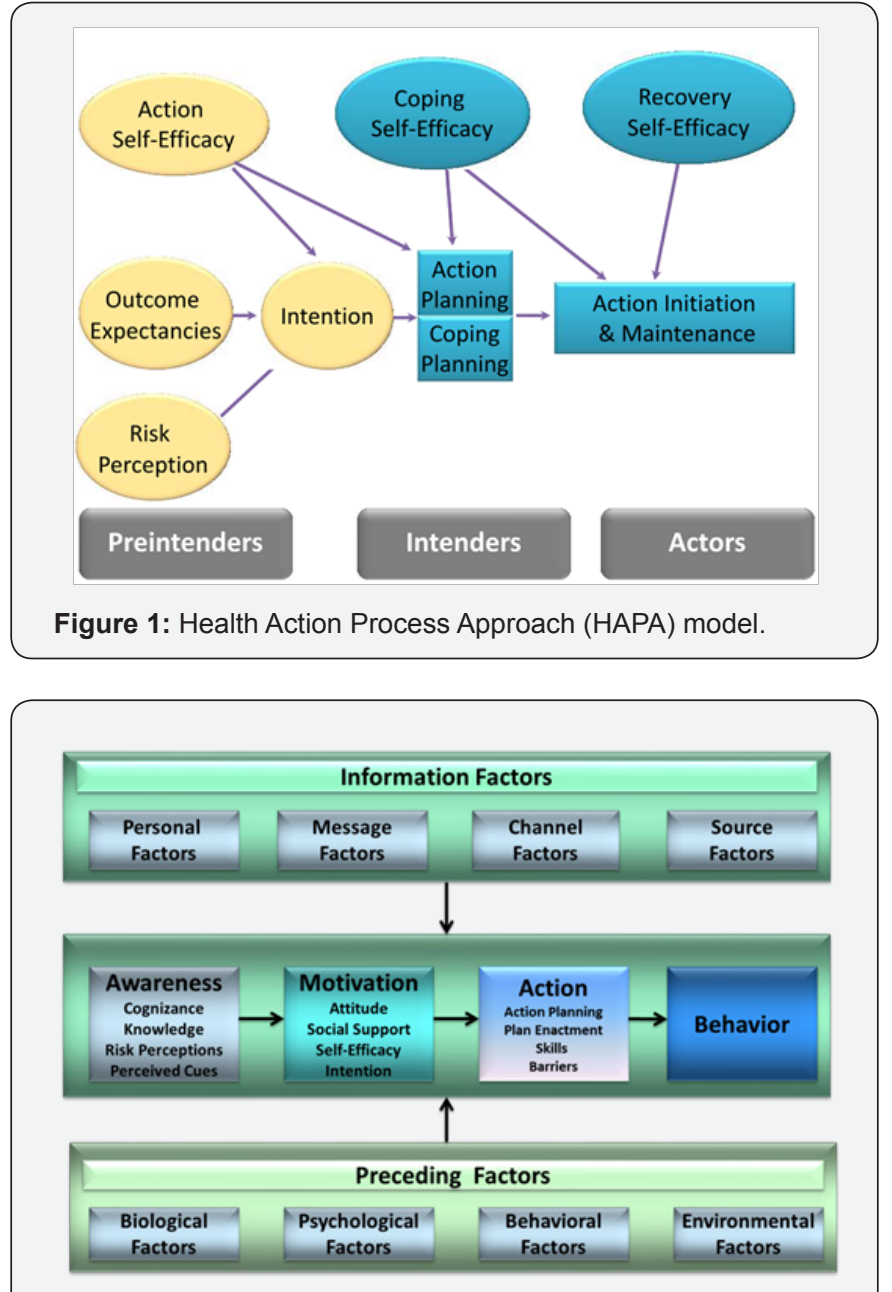

Figure 1: The I-Change Model.

The scope for integrating models can and should not be limited to psychological models. Ecological models have become very popular in health promotion, starting with the PRECEDEPROCEED model [69] and followed by others e.g. [70,71] and assume reciprocal influences between factors. Ecological models have similarities with network approaches, and outline the importance of interactions between social capital and belief development [72]. Network approaches imply the existence of networks of interconnected entities (e.g. cognitions, emotions, friends, psychological traits) that can differ from person to person [73-75]. As these network structures differ from person to person, this signifies a need for highly personalized tailored approaches for behavior change interventions [76]. Ecological applications using the I-Change Model found interactions between the (social) environment and a person, showing, for instance, that parents influence belief development in children and selection of friends [77], and children's behavior also influences parenting [78]. 


\section{Conclusion}

Some scholars argue against integrating theories as this may result in a theory of everything, and recommend to let theories exist and to allow differences in predictions even when similar constructs are used [79]. Yet, the latter recommendation has a couple of hazards. First, this allows the existence of bad theories. Second, if similar theories predict different outcomes, critical testing assessing conditions under which theory ' $\mathrm{A}$ ' or theory ' $B$ ' will be supported, will yield valuable information of working mechanisms and the importance of third factors and interaction effects. So, let's turn the risk into an opportunity and test and compare them. Third, both researchers as practitioners may need guidelines on how to proceed best in order to solve health behavior problems. Allowing co-existence of theories with different or opposite predictions can be confusing for both groups. Fourth, health behavior problems are multifaceted and require an ecological integrative approach addressing the interplay between the environment and a person.

A danger of ecological models can be that they become very global without specific testable assumptions. Yet, when a problem is clearly specified this should yield a focused search of relevant factors related with this problem. Hence, an ecological integrative approach does not necessarily lead to a theory of everything, but to a critical integration of theories relevant to understand and solve a problem. Researchers also need to skip the additive main factor paradigm and are stimulated to adopt an interactive paradigm which may yield more details under which conditions certain factors are important to predict health behavior [60]. Lastly, integration of theories is a complex challenge where integration should not result in loss of depth and detail [80]. It requires a problem based learning approach where integration should clearly lead to testable hypotheses, integration of findings and added value.

\section{References}

1. Bandura A (1986) Social foundations of thought and action: A social cognitive perspective. Englewood Cliffs, NJ: Princeton-Hall.

2. Janz NK, Becker MH (1984) The health belief model: A decade later. Health Educ Q 11(1): 1-47.

3. Ajzen I (1991) The theory of planned behavior. Organizational behavior and human decision processes 50(2): 179-211.

4. Prochaska JO, DiClemente CC (1986) Toward a comprehensive model of change. Treating addictive behaviors: Springer p. 3-27.

5. Fishbein M, Ajzen I (1977) Belief, attitude, intention, and behavior: An introduction to theory and research. Philosophy \& Rhetoric 10(2): 130-132.

6. Conner M, Armitage CJ (1998) Extending the theory of planned behavior: A review and avenues for further research. Journal of applied social psychology 28(15): 1429-1464.

7. Sniehotta FF, Presseau J, Araújo-Soares V (2014) Time to retire the theory of planned behaviour. Health Psychology Review 8(1).

8. Sutton S (2001) Back to the drawing board? A review of applications of the transtheoretical model to substance use. Addiction 96(1): 175186.

9. Dijkstra A, Bakker M, De Vries H (1997) Subtypes within a sample of precontemplating smokers: A preliminary extension of the stages of change. Addict Behav 22(3): 327-337.

10. Kremers SP, Mudde AN, de Vries H (2001) Subtypes within the precontemplation stage of adolescent smoking acquisition. Addict behav 26(2): 237-251.

11. Eldredge LKB, Markham CM, Kok G, Ruiter RA, Parcel GS (2016) Planning health promotion programs: an intervention mapping approach: John Wiley \& Sons.

12. Michie S, West R, Campbell R, Brown J, Gainforth H (2014) ABC of behaviour change theories: Silverback Publishing.

13. Weinstein ND (1993) Testing four competing theories of healthprotective behavior. Health psychol 12(4): 324-333.

14. Fishbein M, Triandis HC, Kanfer FH, Becker M, Middlestadt SE (2001) Factors influencing behavior and behavior change.

15. Noar SM, Zimmerman RS (2005) Health Behavior Theory and cumulative knowledge regarding health behaviors: are we moving in the right direction? Health Educ Res 20(3): 275-290.

16. Schüz B, Sniehotta FF, Mallach N, Wiedemann AU, Schwarzer R (2009) Predicting transitions from preintentional, intentional and actional stages of change. Health Education Research 24(1): 64-75.

17. Johnston M, Dixon D, Hart J, Glidewell L, Schröder C, et al. (2014) Discriminant content validity: A quantitative methodology for assessing content of theory-based measures, with illustrative applications. Br J Health Psychol 19(2): 240-257.

18. Johnston M, Dixon D (2008) Current issues and new directions in psychology and health: What happened to behaviour in the decade of behaviour? Psychol Health 23(5): 509-513.

19. Abraham C (2016) Charting variability to ensure conceptual and design precision: a comment on Ogden. Health psychology review 10(3): 260-264.

20. De Vries H (2017) An integrated approach for understanding health behavior; the I-Change Model as an example. Psychology and Behavioral Science International Journal (in press).

21. Velicer WF, DiClemente CC, Prochaska JO, Brandenburg N (1985) Decisional balance measure for assessing and predicting smoking status. J Pers Soc Psychol 48(5): 1279-1289.

22. Herzog TA, Abrams DB, Emmons KM, Linnan LA, Shadel WG (1999) Do processes of change predict smoking stage movements? A prospective analysis of the transtheoretical model. Health Psychol 18(4): 369-375.

23. Marshall SJ, Biddle SJ (2001) The transtheoretical model of behavior change: a meta-analysis of applications to physical activity and exercise. Ann Behav Med 23(4): 229-246.

24. Guo B, Aveyard P, Fielding A, Sutton S (2009) Do the Transtheoretical Model processes of change, decisional balance and temptation predict stage movement? Evidence from smoking cessation in adolescents. Addiction 104(5): 828-838.

25. De Vries H, Backbier E, Kok G, Dijkstra M (1995) The Impact of Social Influences in the Context of Attitude, Self-Efficacy, Intention, and Previous Behavior as Predictors of Smoking Onset. Journal of applied social psychology 25(3): 237-257.

26. Verplanken B, Aarts H, Knippenberg A, Moonen A (1998) Habit versus planned behaviour: A field experiment. Br J Soc Psychol 37(1): 111128. 
27. Gardner B, de Bruijn GJ, Lally P (2012) Habit, identity, and repetitive action: A prospective study of binge-drinking in UK students. Br J Health Psychol 17(3): 565-581.

28. De Bruijn GJ (2010) Understanding college students' fruit consumption. Integrating habit strength in the theory of planned behaviour. Appetite 54(1): 16-22.

29. De Vries H, Eggers SM, Lechner L, van Osch L, van Stralen MM (2014) Predicting fruit consumption: the role of habits, previous behavior and mediation effects. BMC public health 14(1): 730.

30. van Bree RJ, van Stralen MM, Mudde AN, Bolman C, de Vries H, et al (2015) Habit as mediator of the relationship between prior and later physical activity: A longitudinal study in older adults. Psychology of Sport and Exercise 19: 95-102.

31. Janis IL, Mann L (1977) Decision making: A psychological analysis of conflict, choice, and commitment: Free press. The Academy of Management Review 5(1): 141-143.

32. Dijkstra A, De Vries H, Bakker M (1996) Pros and cons of quitting, selfefficacy, and the stages of change in smoking cessation. J Consult Clin Psychol 64(4): 758-763.

33. Holm K, Kremers SP, De Vries H (2003) Why do Danish adolescents take up smoking? Eur J Public Health 13(1): 67-74.

34. De Vries H, Mudde AN, Dijkstra A, Willemsen MC (1998) Differential beliefs, perceived social influences, and self-efficacy expectations among smokers in various motivational phases. Prev Med 27(5): 681689.

35. Bolman C, de Vries H (1998) Psycho-social determinants and motivational phases in smoking behavior of cardiac inpatients. Prev Med 27(5): 738-747.

36. van der Pligt J, Richard R (1994) Changing adolescents' sexual behaviour: perceived risk, self-efficacy and anticipated regret. Patient Educ Couns 23(3): 187-196.

37. Lechner L, De Vries H, Offermans N (1997) Participation in a breast cancer screening program: influence of past behavior and determinants on future screening participation. Prev Med 26(4): 473-482.

38. de Nooijer J, Lechner L, de Vries H (2003) Social psychological correlates of paying attention to cancer symptoms and seeking medical help. Soc Sci Med 56(5): 915-920.

39. Knops-Dullens T, de Vries N, de Vries H (2007) Reasons for nonattendance in cervical cancer screening programmes: an application of the Integrated Model for Behavioural Change. Eur J Cancer Prev 16(5): 436-445.

40. Rivis A, Sheeran P (2003) Descriptive norms as an additional predictor in the theory of planned behaviour: A meta-analysis. Current Psychology 22(3): 218-233.

41. Trafimow D, Sheeran P, Conner M, Finlay KA (2002) Evidence that perceived behavioural control is a multidimensional construct: Perceived control and perceived difficulty. Br J Soc Psychol 41(1): 101121.

42. De Vries H, Mudde AN (1998) Predicting stage transitions for smoking cessation applying the attitude-social influence-efficacy model. Psychology and Health 13(2): 369-385.

43. Hoving E, Mudde A, De Vries H (2006) Smoking and the $\emptyset$ pattern; predictors of transitions through the stages of change. Health Educ Res 21(3): 305-314.

44. De Vries H, van Osch L, Eijmael K, Smerecnik C, Candel M (2012) The role of risk perception in explaining parental sunscreen use. Psychol Health 27(11): 1342-1358.
45. Eggers SM, Aarø LE, Bos AE, Mathews C, Kaaya SF, et al. (2016) Sociocognitive predictors of condom use and intentions among adolescents in three sub-saharan sites. Arch Sex Behav 45(2): 353-365.

46. Sheeran Paschal (2002) Intention-behavior relations: A conceptual and empirical review. European review of social psychology 12(1): $1-36$.

47. De Vries H, Mesters I, van't Riet J, Willems K, Reubsaet A (2006) Motives of Belgian adolescents for using sunscreen: the role of action plans. Cancer Epidemiol Biomarkers Prev 15(7): 1360-1366.

48. Kwasnicka D, Presseau J, White M, Sniehotta FF (2013) Does planning how to cope with anticipated barriers facilitate health-related behaviour change? A systematic review. Health psychology r e v i e w 7(2): 29-145.

49. Weinstein ND (1988) The precaution adoption process. Health Psychol $7(4): 355-386$.

50. De Vries H, Mudde A, Leijs I, Charlton A, Vartiainen E, et al. (2003) The European Smoking prevention Framework Approach (EFSA): an example of integral prevention. Health Educ Res 8(5): 611-626.

51. De Vries H, Mesters I, Van de Steeg H, Honing C (2005) The general public's information needs and perceptions regarding hereditary cancer: an application of the Integrated Change Model. Patient Educ Couns 56(2): 154-165.

52. Schwarzer R, Lippke S, Luszczynska A (2011) Mechanisms of health behavior change in persons with chronic illness or disability: the Health Action Process Approach (HAPA). Rehabil Psychol 6(3): 161170 .

53. Heckhausen H, Gollwitzer PM (1987) Thought contents and cognitive functioning in motivational versus volitional states of mind. Motivation and emotion 11(2): 101-120.

54. Dijkstra A, Conijn B, De Vries H (2006) A match-mismatch test of a stage model of behaviour change in tobacco smoking. Addiction 101(7): 1035-1043.

55. De Vries H, Kremers S, Smeets T, Brug J, Eijmael K (2008) The effectiveness of tailored feedback and action plans in an intervention addressing multiple health behaviors. Am J Health Promot 22(6): 417 425.

56. De Vries H, Lezwijn J, Hol M, Honing C (2005) Skin cancer prevention: behaviour and motives of Dutch adolescents. Eur J Cancer Prev 14(1): 39-50.

57. Hoving E, Mudde A, De Vries H (2006) Predictors of smoking relapse in a sample of Dutch adult smokers; the roles of gender and action plans. Addict Behav 31(7): 1177-1189.

58. Van Osch L, Lechner L, Reubsaet A, Wigger S, Vries H (2008) Relapse prevention in a national smoking cessation contest: effects of coping planning. Br J Health Psychol 13(3): 525-535.

59. De Vries H, Eggers SM, Bolman C (2013) The role of action planning and plan enactment for smoking cessation. BMC Public Health 13(1): 393.

60. De Vries H (2016) Self-efficacy: skip the main factor paradigm! A comment on Williams and Rhodes (2016). Health Psychol Rev 10(2): 140-143.

61. Elfeddali I, Bolman C, Candel MJ, Wiers RW, De Vries H (2012) The role of self-efficacy, recovery self-efficacy, and preparatory planning in predicting short-term smoking relapse. Br J Health Psychol 17(1): 185-201.

62. Gutiérrez-Doña B, Lippke S, Renner B, Kwon S, Schwarzer R (2009) Self-Efficacy and Planning Predict Dietary Behaviors in Costa Rican 
and South Korean Women: Two Moderated Mediation Analyses. Applied Psychology: Health and Well-Being 1(1): 91-104.

63. Lippke S, Wiedemann AU, Ziegelmann JP, Reuter T, Schwarzer R (2009) Self-efficacy moderates the mediation of intentions into behavior via plans. Am J Health Behav 33(5): 521-529.

64. Luszczynska A, Schwarzer R, Lippke S, Mazurkiewicz M (2011) Selfefficacy as a moderator of the planning-behaviour relationship in interventions designed to promote physical activity. Psychol Health 26(2): 151-166

65. Dijkstra A, Vries HD (2000) Self-efficacy expectations with regard to different tasks in smoking cessation. Psychology and Health 15(4): 501-511.

66. Schwarzer R (2008) Modeling health behavior change: How to predict and modify the adoption and maintenance of health behaviors. Applied Psychology 57(1): 1-29.

67. Hagger MS, Chatzisarantis NL (2009) Integrating the theory of planned behaviour and self-determination theory in health behaviour: A metaanalysis. Br J Health Psychol 14(2): 275-302.

68. Deci EL, Ryan RM (2000) The" what" and" why" of goal pursuits: Human needs and the self-determination of behavior. Psychological inquiry 11(4): 227-268.

69. Green LW, Kreuter MW (2005) Health program planning: An educational and ecological approach.

70. Sallis JF, Cervero RB, Ascher W, Henderson KA, Kraft MK, et al. (2006) An ecological approach to creating active living communities. Annu Rev Public Health 27: 297-322.

71. Kremers SP, De Bruijn GJ, Visscher TL, Van Mechelen W, De Vries NK, et al. (2006) Environmental influences on energy balance-related behaviors: a dual-process view. Int J Behav Nutr Phys Act 3(1): 9.
72. Henry AD, Lubell M, McCoy M (2011) Belief systems and social capital as drivers of policy network structure: The case of California regional planning. J Public Adm Res Theory 21(3): 419-444.

73. French DP, Marteau TM, Senior V, Weinman J (2002) The structure of beliefs about the causes of heart attacks: a network analysis. $\mathrm{Br} \mathrm{J}$ Health Psychol 7(4): 463-479.

74. Mercken L, Snijders TA, Steglich C, De Vries H (2009) Dynamics of adolescent friendship networks and smoking behavior: Social network analyses in six European countries. Soc Sci Med 69(10): 1506-1514.

75. Green D, McManus I (1995) Cognitive structural models: The perception of risk and prevention in coronary heart disease. Br J Psychol 86: 321-336.

76. Schulz DN, Kremers SP, Vandelanotte C, Van Adrichem MJ, Schneider F, et al. (2014) Effects of a web-based tailored multiple-lifestyle intervention for adults: a two-year randomized controlled trial comparing sequential and simultaneous delivery modes. J Med Internet Res 16(1):e26.

77. De Vries H, Candel M, Engels R, Mercken L (2006) Challenges to the peer influence paradigm: results for 12-13 year olds from six European countries from the European Smoking Prevention Framework Approach study. Tob Control 15(2): 83-89.

78. Huver RM, Engels RC, Vermulst AA, De Vries H (2007) Bi-directional relations between anti-smoking parenting practices and adolescent smoking in a Dutch sample. Health Psychology 26(6): 762-768.

79. Peters GJ, Kok G (2016) All models are wrong, but some are useful: a comment on Ogden (2016). Health Psychol Rev 10(3): 265-268.

80. Teixeira PJ (2016) Health behavior change: a field just picking up speed. A comment on Ogden (2016). Health Psychol Rev 10(3): 269273.

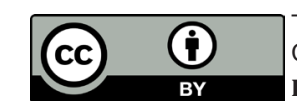

This work is licensed under Creative Commons Attribution 4.0 License

DOI:10.19080/PBSIJ.2017.02.555585

\section{Your next submission with Juniper Publishers} will reach you the below assets

- Quality Editorial service

- Swift Peer Review

- Reprints availability

- E-prints Service

- Manuscript Podcast for convenient understanding

- Global attainment for your research

- Manuscript accessibility in different formats

( Pdf, E-pub, Full Text, Audio)

- Unceasing customer service

Track the below URL for one-step submission https://juniperpublishers.com/online-submission.php 